\title{
Putting Radon to Work: Identifying Coastal Ground-Water Discharge Sites
}

\author{
By John Crusius, John Bratton, and Matt Charette
}

When most people think of radon they think of the naturally occurring, odorless, radioactive gas that can cause health problems when it reaches unsafe levels in basements. The health hazard arises because radon gas is continuously produced from ubiquitous materials in the soil and can build up to high levels in the pore spaces, and then migrate through cracks and fissures into basements. Similarly, radon is often present at high levels in ground water.

In contrast, radon is present at much lower levels in seawater; therefore, it is an excellent tracer of ground-water discharge to the coastal ocean. With this application in mind, a team of scientists at the USGS Woods Hole Science Center and the Woods Hole Oceanographic Institution (WHOI) set out to put radon to work by developing a system for mapping radon activities in coastal waters. Prof. Bill Burnett, of Florida State University, has independently developed a similar radon mapping system.

In recent years it has become increasingly clear that submarine groundwater discharge plays an important role delivering water and nutrients to coastal waters (see http://soundwaves. usgs.gov/2004/06/research4.html). Ground-water derived nutrient discharge is often significant because nutrient concentrations can be far greater in ground water than in surface waters. Elevated nutrient loads, primarily in the forms of nitrate and ammonium ion, can fuel problematic algal blooms. Identifying locations of coastal ground-water discharge has proven difficult, however, because the discharge is typically diffuse and below the water surface. New techniques for locating and quantifying this discharge are clearly needed.

Surface-water radon mapping provides one such new tool. Radon is radioactive, and its activity, rather than its concentration, is used to measure its presence. It is the large difference between ground-water and surface-water activities, together with radon's inert geochemical behavior, that allow us to identify ground-water discharge sites and potentially to quantify the rate of discharge.

Although techniques for measuring radon have existed for many years, the older methods are time-consuming and labor-intensive. Newer technology allows rapid, in situ measurement (in 30-60 minutes, depending on the activity), permitting data collection at far greater spatial resolution than was previously possible.

The new radon mapping system works as follows. A submerged pump transfers seawater at a rate of a few liters per minute to a spray chamber that extracts radon from the water into the gas phase (Figure 1). The spray chamber is connected to a series of four radon analyzers (Figure 2), each of which measures the radon activity of the gas from the spray chamber during overlapping time periods. In this manner, estimates of the average radon activity can be generated every 5-10 minutes. In addition, navigation, depth, salinity, and temperature measurements are made at least once each minute. All the data can be monitored with a shipboard computer and recorded in real time to a data file

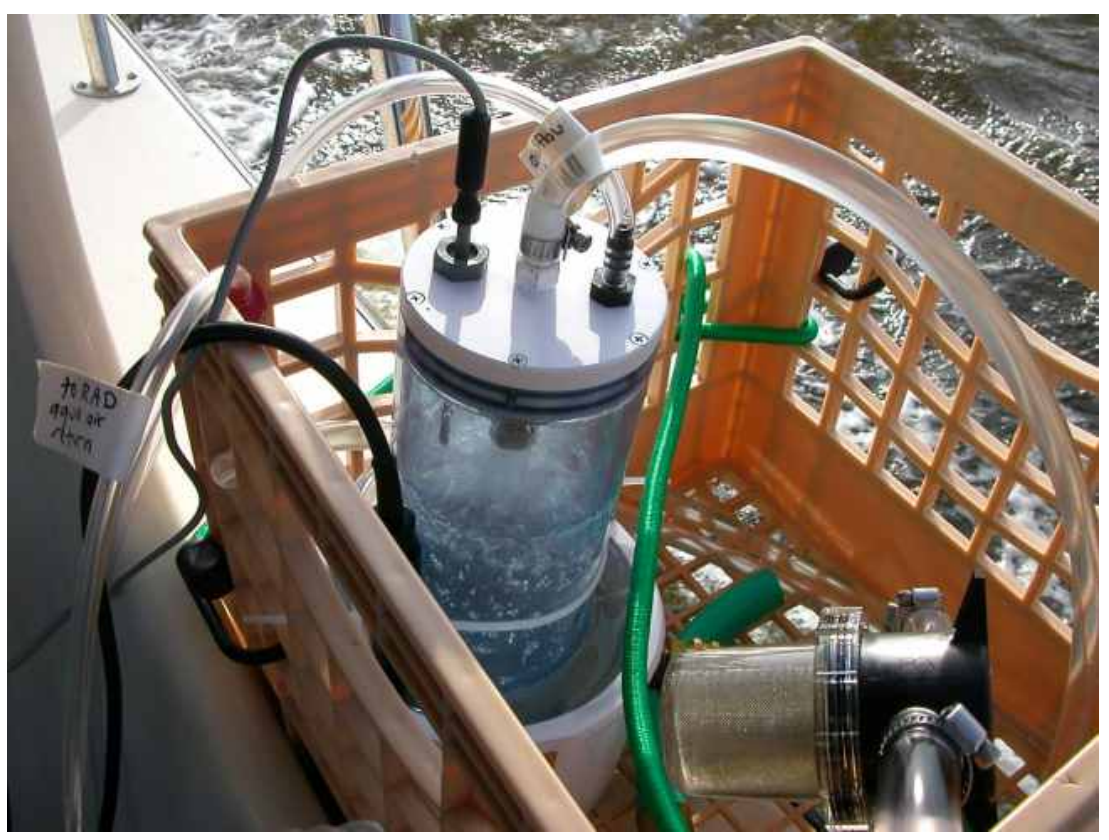

Figure 1. Air-water equilibrator that transfers radon from surface water into the gas phase. Water is pumped into the device and sprayed in a fine mist from a nozzle at the top. The gas phase is pumped to the radon detector (Figure 2). 
using software developed for this project. The geographical distribution of these data can then be plotted using conventional mapping software. The spatial resolution achievable is limited only by the boat speed in relation to the equilibration time of approximately twenty minutes required for the system to adjust to new radon levels.

The first field test of the new system for mapping radon activities was performed in Waquoit Bay and surrounding estuaries on Cape Cod, Massachusetts. The data reveal extremely high radon activities in the Childs River estuary west of the bay (Figure 3), evidence of considerable ground-water discharge in that region. By contrast, radon activities in the estuaries immediately east of Waquoit Bay are far lower than those in the Childs River. Determining the reasons for these differences will require additional study.

The radon mapping system is a valuable new tool for identifying locations of ground-water discharge. It complements the electrical resistivity technique (http://soundwaves.usgs.gov/ 2004/06/fieldwork.html), which distinguishes the higher electrical resistance of fresh ground water beneath

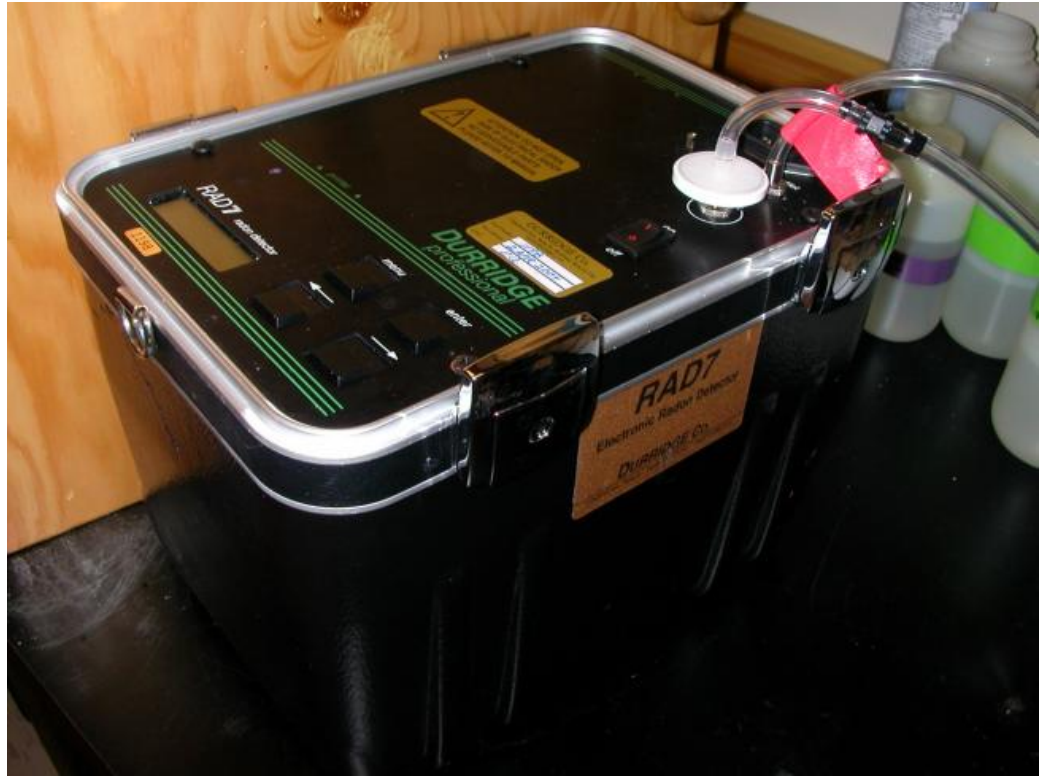

Figure 2. RAD7 portable radon detector (made by Durridge Company, Bedford, Massachusetts). A pump circulates gas to the detector in a closed loop connected to the air-water equilibrator (Figure 1). estuaries compared with that of salty ground water. Together, these new technologies offer unprecedented sophistication for pinpointing groundwater discharge sites using rapid regional surveys. Once they are found, sites can then be studied in greater detail to characterize their geochemistry and to quantify the flux of water and nutrients

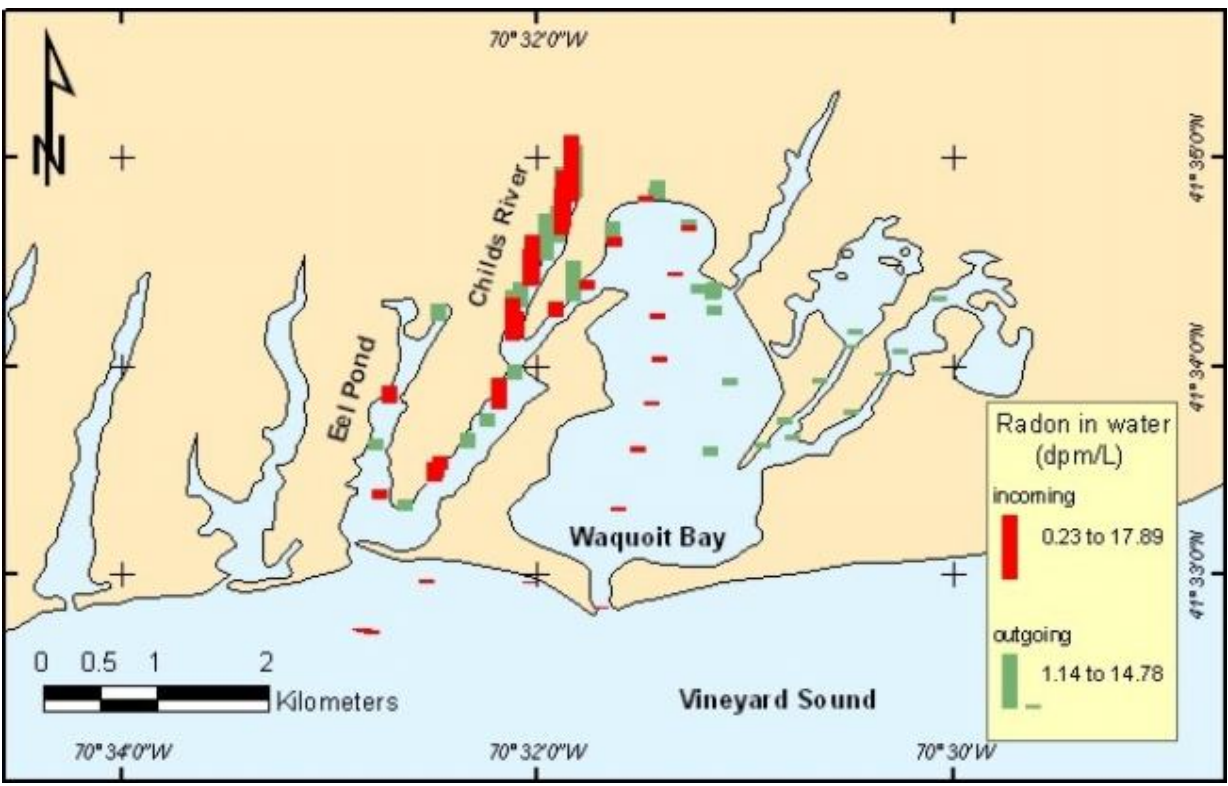

Figure 3. Map of radon activities in and around Waquoit Bay, Cape Cod, Massachusetts generated during a one-day survey $(\mathrm{dpm} / \mathrm{L}=$ decays per minute per liter of water). The red bar lengths are scaled proportionally to the radon activities measured as the vessel traveled into the study area, from Vineyard Sound to the north end of Eel Pond (the "incoming" transect), and the green bars denote activities measured as the boat traveled back along approximately the same path (the "outgoing" transect). Elevated radon activities at any location are an indication of significant ground-water discharge. from ground water at coastal locations over a particular time period.

Participants in the effort included

John Crusius, John Bratton, Dirk

Koopmans, Kevin Kroeger, Dann

Blackwood, Sarah Kelsey, and VeeAnn

Cross from the USGS Woods Hole

Science Center, and Matt Charette,

Meagan Gonnea, and Ed Hobart from

WHOI. Development and testing of this system was supported by the USGS Geologic Discipline Venture Capital Fund.

(Note: Any use of trade, product, or firm names is for descriptive purposes only and does not imply endorsement by the U.S. Government.)

For more information, please contact: John Crusius ${ }^{1}$ or John Bratton ${ }^{2}$

U.S. Geological Survey

Woods Hole Science Center

Woods Hole, MA 02543-1589

Matt Charette

Woods Hole Oceanographic Institution Dept. of Marine Chemistry \& Geochemistry Woods Hole, MA 02543

Tel: '(508)457-2353 E-mail: ${ }^{j}$ crusius@usgs.gov 2(508)457-2254 2ijbratton@usgs.gov 3(508)289-3205_ 3 mcharette@whoi.edu 